\title{
Pengaruh Segmen Lunak Terhadap Daya Penstabilan Struktur Poliuretan Termosetting Elastomer Berbasis HTPB
}

\author{
Afni Restasari ${ }^{1}$ \\ ${ }^{1}$ Lembaga Penerbangan dan Antariksa Nasional, Desa Mekarsari, Kel. Sukamulya, \\ Kec. Rumpin, Kab. Bogor 16350 \\ Correspondence: Afni Restasari (mathchem2aza@gmail.com) \\ Received: 110621 - Revised: 130821 - Accepted: 100921 - Published: 150921
}

\begin{abstract}
Abstrak. Poliuretan termosetting elastomer berbasis Hydroxyl-terminated polybutadiene (HTPB) merupakan polimer dengan performa yang unggul. Sifat mekaniknya dipengaruhi oleh segmen lunak yang berasal dari rantai hidrokarbon dari HTPB. Dalam penelitian ini, pengaruh segmen lunak terhadap proses penstabilan struktur poliuretan termosetting elastomer berbasis HTPB dilakukan. Segmen lunak divariasi dengan memvariasi berat molekul HTPB yaitu 4536, 7234, $8160 \mathrm{~g} / \mathrm{mol}$. Proses penstabilan struktur diselidiki dengan pemantauan peningkatan kekerasan poliuretan setelah pematangan hingga minggu kedua. Dua jenis poliuretan yang digunakan adalah yang berasal dari suhu proses polimerisasi one-shot pada suhu $50{ }^{\circ} \mathrm{C}$ dan $70{ }^{\circ} \mathrm{C}$. Daya penstabilan dianalisa dari laju peningkatan kekerasan poliuretan. Berdasarkan laju peningkatan kekerasan, diketahui bahwa hubungan antara segmen lunak dengan proses penstabilan kekerasan poliuretan sensitif pada suhu tinggi yang mana poliuretan dengan segmen lunak yang lebih banyak memiliki daya penstabilan struktur yang lebih rendah.
\end{abstract}

Kata kunci: Poliuretan, Polimer, Elastomer, Termosetting, Segmen lunak

Citation Format: Restasari. A (2021). Pengaruh Segmen Lunak Terhadap Daya Penstabilan Struktur Poliuretan Termosetting Elastomer Berbasis HTPB. Prosiding Seminar Nasional Abdimas Ma Chung (SENAM), 2021, 01-10 


\section{PENDAHULUAN}

Polimer komposit adalah material serba guna yang tersusun dari polimer yang diisi oleh partikel baik dalam ukuran mikron maupun nano, baik logam, anorganik maupun organik. Pengembangan teknologi polimer komposit memerlukan acuan sifat mekanik agar material ini dapat berfungsi dengan optimum dalam penggunaannya. Misalnya, dalam pengembangan propelan padat komposit (PPK) sebagai bahan bakar roket, standar sifat mekanik yang diterapkan adalah kuat tarik sekitar 7-8 kgf $/ \mathrm{cm}^{2}$ dan elongasi $40-50 \%$ (Manjari, Joseph, Sarabhai, \& Centre, 1993). Oleh karena dalam pengembangan bahan bakar roket ini sifat mekanik berpengaruh pada keselamatan dan kesuksesan misi mengangkasa (Remakanthan, Kk, Gunasekaran, Thomas, \& Thomas, 2015), perancangan sifat mekanik dan penelitian untuk memahami asal muasal sifat mekanik ini terus dilakukan. Perancangan sifat mekanik sangatlah bergantung pada jenis roket yang akan dipakai. Semakin besar roket, tentunya memerlukan PPK yang besar pula dan syarat elongasi atau persentase kemuluran serta kuat tarik, dan kekerasan yang berbeda dengan syarat untuk PPK berukuran kecil.

Salah satu penentu sifat mekanik PPK adalah polimer. Sesuai dengan jenisnya, polimer komposit, PPK mengandung polimer yaitu poliuretan. Poliuretan dipilih karena polimernya tahan dingin dan tahan air serta cukup baik dalam hal sifat mekanik (Matsunaga, 2010). Polimer ini berasal dari reaksi polimerisasi antara gugus hidroksil dan gugus isosianat. Senyawa yang mengandung gugus hidroksil yang handal digunakan adalah Hydroxyl-terminated polybutadiene (HTPB), sementara senyawa isosianat yang digunakan biasanya adalah Toluena diisosianat (TDI). Dari struktur polimer hasil reaksi polimerisasi ke sifat mekanik poliuretan adalah mekanisme yang rumit.

Proses pembentukan ikatan uretan yang diaplikasikan adalah teknik one-shot, yaitu HTPB dan TDI dicampur dalam satu waktu. Oleh karena teknik one-shot ini, empat kemungkinan reaksi polimerisasi dapat terjadi, seperti dijabarkan pada Gambar 1. Pada gambar tersebut, reaksi awal pembentukan ikatan uretan adalah persamaan 1. Persamaan 2, 3 dan 4 adalah kelanjutan dari persamaan reaksi 1. Persamaan 2 ialah mekanisme yang terjadi apabila poliuretan bereaksi dengan gugus NCO dari TDI sehingga terbentuk poliuretan yang memiliki gugus NCO di kedua ujungnya. Sementara, pada persamaan 3, poliuretan bereaksi dengan gugus OH dari HTPB sehingga dihasilkan poliuretan dengan gugus $\mathrm{OH}$ di kedua ujungnya. Persamaan 4 terjadi apabila gugus uretan bereaksi dengan NCO dari TDI (Wibowo, 2015). 


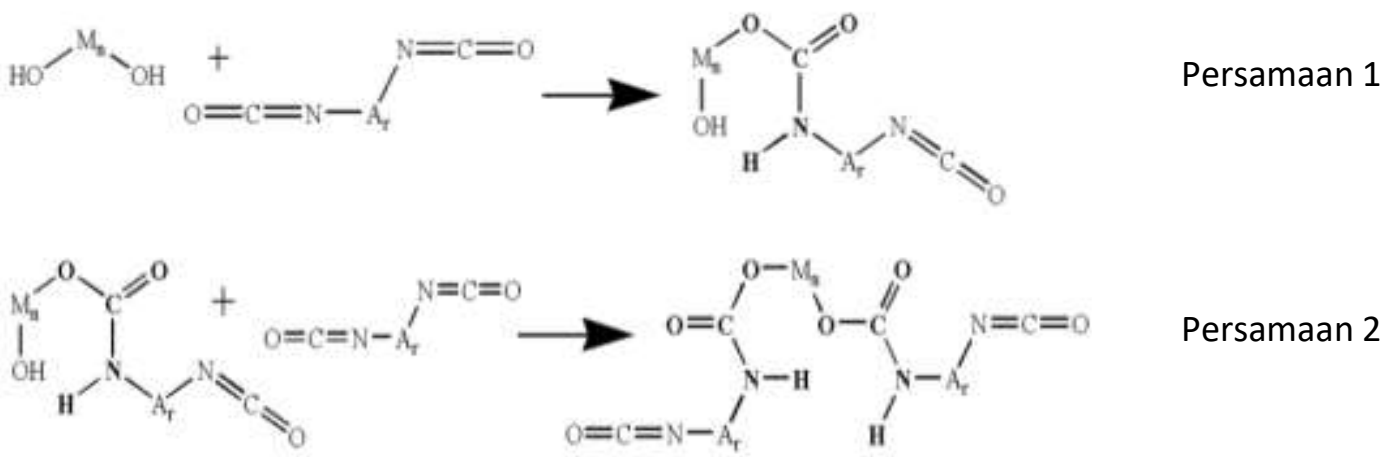

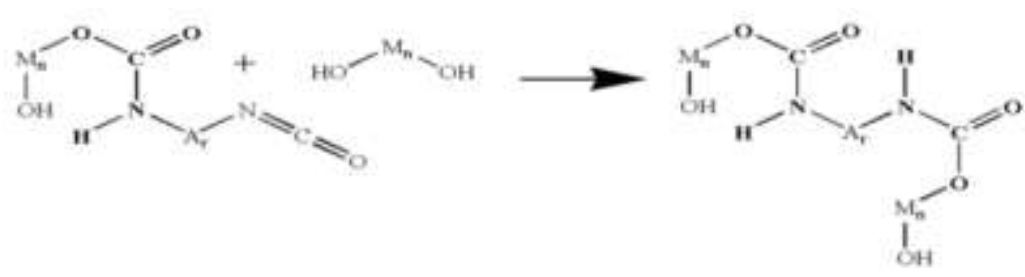

Persamaan 3<smiles>[Y19]OC(=O)N([TlH])[Y]N=C=O</smiles>

Persamaan 4

Gambar 1. Berbagai reaksi polimerisasi poliuretan (Wibowo, 2015).

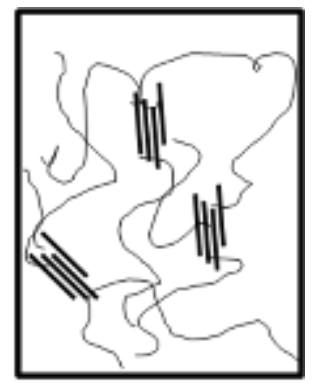

Gambar 2. Higher-order Structure dari poliuretan tersegmentasi (Satoshi, 2018).

Setelah polimer poliuretan terbentuk melalui polimerisasi, proses selanjutnya adalah pembentukan higher-order structure dan penstabilannya. Dalam higher-order structure, poliuretan termosetting elastomer yang digunakan untuk PPK terdiri dari segmen lunak dan keras. Segmen lunak berasal dari rantai panjang hidrokarbon polimer (Satoshi, 2018). Dalam hal HTPB, segmen lunak ini sangatlah kompleks karena rantai panjang hidrokarbon HTPB terdiri dari isomer cis, vinil, trans seperti pada Gambar 3 yang mana sifat isomer cis 
dan trans berbeda dengan vinil. Dengan asumsi bahwa hidrokarbon HTPB seperti hidrokarbon polibutadiena, nilai koefisien gesek isomer cis dan trans berbeda dengan vinil yaitu $\log \xi_{0}=-6.75$ dynes-sec/cm pada $25{ }^{\circ} \mathrm{C}$ dan $\xi_{0}=-4.11$ dynes-sec/cm. Volume bebasnya pun berbeda untuk cis dan trans dengan vinil, yaitu 6,1 dan 3,9 pada $25{ }^{\circ} \mathrm{C}$ and $G^{\prime}=108$ dyne $/ \mathrm{cm}^{2}$ (Ferry, 1980). Isomer vinil sendiri memiliki tiga stereoisomer yaitu isotaktik, sindiotaktik dan ataktik seperti disajikan pada Gambar 4.

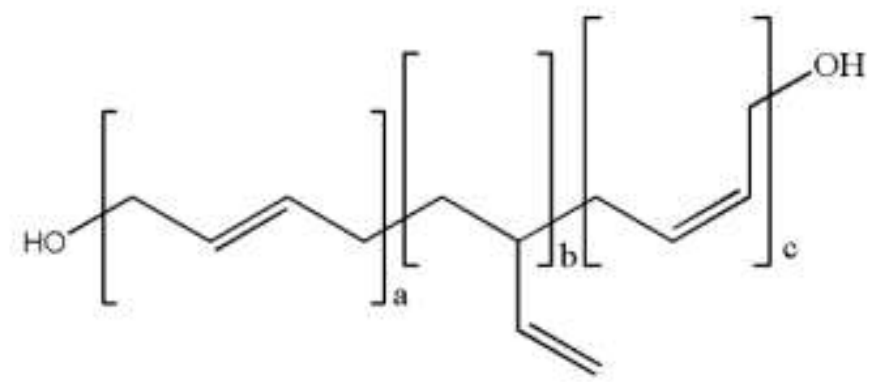

Gambar 3. Mikrostruktur isomer HTPB: 1,4-trans (a), 1,4-cis (b) dan 1,2-vinyl (c) (Dey, Sikder, \& Athar, 2017).
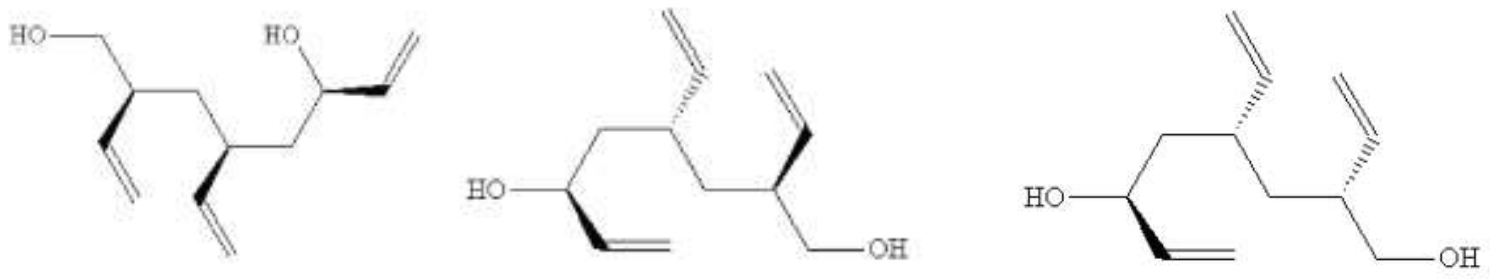

Gambar 4. Stereoisomer struktur vinil dari HTPB: Isotaktik (kiri), Sindiotaktik (tengah), Ataktik (kanan) (Dey et al., 2017).

Sementara, segmen keras merupakan kumpulan dari bagian polimer yang mengandung gugus uretan. Gaya yang bekerja pada perkumpulan ini adalah ikatan fisik hidrogen yang membentuk kohesivitas. Gaya kohesif dari gugus uretan adalah sebesar 8.74 kcal/mol, sementara dengan digunakannya TDI yang memiliki struktur benzena, gaya tersebut mendapat tambahan sebesar $3.9 \mathrm{kcal} / \mathrm{mol}$ (Matsunaga, 2010). Ilustrasi segmen keras dan lunak ini dapat dilihat di Gambar 2. Panjang segmen lunak sekitar 1000- 2000 nm. Sedangkan segmen keras sekitar $150 \mathrm{~nm}$ (Hepburn, 1992) dan berbentuk seperti misel berumbai (Satoshi, 2018). Sifat mekanik poliuretan dipengaruhi oleh higher-order structure tersebut.

Selama ini, penelitian mengenai efek higher-order structure terhadap sifat mekanik yang dilakukan hanya sebatas sifat akhir dari poliuretan. Contohnya, penelitian yang 
dilakukan Dey et al (2017) yang mana menyebutkan bahwa isomer cis bertanggungjawab pada keelastisan poliuretan, sementara trans bertanggungjawab pada kekakuan poliuretan (Dey, Athar, Sikder, \& Chattopadhyay, 2015; Dey et al., 2017). Sedangkan, penelitian yang menyibak bagaimana higher-order structure mempengaruhi sifat mekanik jarang dilakukan.

Satoshi (2018) mendeskripsikan higher-order structure poliuretan seperti lautan yang berpulau. Lautan tersebut adalah segmen lunak, sedangkan pulaunya adalah segmen keras. Oleh karena bagian yang sulit bergerak adalah segmen keras maka sifat mekanik poliuretan ditentukan oleh bagaimana segmen keras tersebut bertransformasi dengan teknik polimerisasi dan pematangan yang diaplikasikan. Proses transformasi ini dibuktikan dengan dibutuhkannya waktu untuk mendapatkan struktur yang stabil, tidak berubah, setelah pemanasan (Satoshi, 2018). Namun demikian, dengan memperhatikan struktur isomer dan stereoisomer dari hidrokarbon HTPB yang kompleks, segmen lunak diprediksi memiliki daya penstabilan terhadap sifat mekanik poliuretan dengan mekanisme seperti menghalangi atau memudahkan transformasi bentuk dari segmen keras sehingga sifat mekanik dapat lambat atau cepat stabil.

Dengan demikian, penelitian ini bertujuan untuk mengetahui pengaruh segmen lunak, dengan memvariasi berat molekul HTPB, terhadap proses penstabilan sifat mekanik poliuretan. Sifat mekanik yang dipilih adalah kekerasan karena mudah untuk diuji dan praktis dalam aplikasinya. Metode yang digunakan berupa pemonitoran dan analisa pola peningkatan kekerasan selama beberapa hari setelah pematangan. Oleh karena pergerakan molekul dipengaruhi oleh temperatur, variasi temperatur juga diterapkan.

\section{METODE PELAKSANAAN}

Dalam penelitian ini, enam buah poliuretan digunakan. Tiga buah berasal dari proses pembuatan pada suhu $50{ }^{\circ} \mathrm{C}$. Tiga yang lain berasal dari proses pembuatan pada suhu 70 ${ }^{\circ} \mathrm{C}$. Ketiga poliuretan berasal dari HTPB yang berbeda yaitu HTPB A, B, C dengan berat molekul masing - masing adalah 4536, 7234, $8160 \mathrm{~g} / \mathrm{mol}$. HTPB A diproduksi oleh Hanwha Co Ltd. Sementara HTPB C dibuat oleh Dalian Chlorate Ltd. HTPB B dibuat dengan mencampur kedua bahan tersebut. Selain HTPB, poliuretan tersebut juga dibuat dari Toluena diisosianat (TDI) berisomer 2,4-TDI sebesar $80.5 \%$ dan isomer 2,6-TDI sebesar 19.5\%. Perbandingan HTPB:TDI adalah 14:1. 
Metode yang dilakukan meliputi pengukuran kekerasan dengan menggunakan Durometer shore A. Pemilihan Durometer tipe shore A karena jangkauan nilai kekerasannya meliputi kekerasan semua elastomer. Pengukuran dilakukan pada hari kesatu, ketujuh dan keempatbelas. Setiap pengukuran diulang 3 kali agar hasil lebih akurat. Kestabilan struktur high-order diwakili oleh laju peningkatan kekerasan $(k)$ dari persamaan (1) di bawah ini yang mana $t$ adalah dalam hari. Semakin tinggi $k$, semakin rendah daya penstabilan struktur.

$\ln ($ kekerasan $)=k t+\ln ($ kekerasan awal $)$

\section{HASIL DAN PEMBAHASAN}

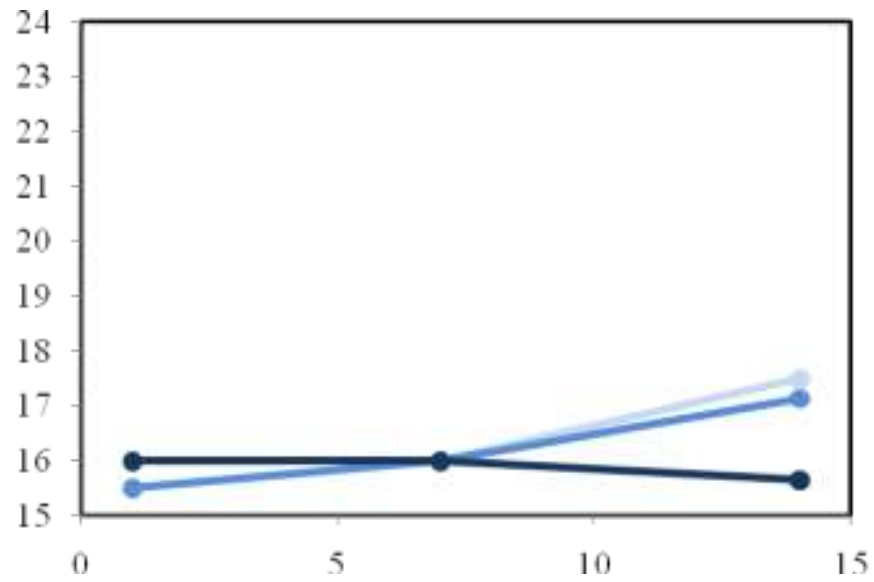

Gambar 1. Pola peningkatan kekerasan dengan suhu proses $50{ }^{\circ} \mathrm{C}$. Poliuretan A, B, C dengan semakin meningkatnya segmen lunak, diwakili dengan gradasi warna dari muda ke gelap.

Tabel 1. Tabel laju peningkatan viskositas dengan suhu proses $50{ }^{\circ} \mathrm{C}$

\begin{tabular}{cccccc}
\hline Poliuretan & $M_{w}$ & $k$ & $\begin{array}{c}\text { ln kekerasan } \\
\text { awal }\end{array}$ & $R^{2}$ & $\begin{array}{c}\text { Tingkatan } \\
\text { korelasi }\end{array}$ \\
\hline A & 4536 & 0 & 2.778 & 0.787 & tinggi \\
B & 6348 & 0.007 & 2.727 & 0.972 & tinggi \\
C & 8160 & 0.007 & 2.75 & 0.787 & tinggi \\
\hline
\end{tabular}

Pada penelitian ini diselidiki pengaruh segmen lunak terhadap proses penstabilan sifat mekanik poliuretan berbasis HTPB. Besarnya segmen lunak diwakili dengan digunakannya HTPB dengan berbagai berat molekul sebagai sampel. Dari poliuretan A hingga $\mathrm{C}$ secara berturut-turut mengandung arti bahwa persentase segmen lunak semakin besar. Sementara, untuk mengetahui pola penstabilan sifat mekanik poliuretan, dilakukan 
pemonitoran dan analisa pola peningkatan kekerasan selama beberapa minggu setelah pematangan.

Gambar 1 menunjukkan pola peningkatan kekerasan dari poliuretan A, B, C dengan suhu proses $50{ }^{\circ} \mathrm{C}$. Persamaan linier yang dihasilkan disebutkan pada Tabel 1 . Terobservasi pada Gambar 1 bahwa kekerasan ketiga jenis poliuretan berkisar antara 15 - 19 shore A. Nilai kekerasan itu menunjukkan bahwa polimerisasi sudah berhasil dan gugus uretan sukses terbentuk karena diketahui bahwa kekerasan senyawa poliuretan elastomer adalah 10 - 100 shore A (Matsunaga, 2010) dan poliuretan berbasis HTPB dengan suhu proses 45 ${ }^{\circ} \mathrm{C}$ pernah dilaporkan memiliki kekerasan 10 - 20 shore A (Afni Restasari \& Abdillah, 2017). Secara umum tidak ada perbedaan signifikan dengan pola peningkatan kekerasan terhadap ketiga jenis poliuretan. Hal ini diperkuat dengan nilai $k$ yang mirip untuk ketiga poliuretan, tersaji pada Tabel 1. Nilai $k$ ini akurat karena pola garis pada Gambar 1 berhasil membentuk korelasi linier dengan tingkatan korelasi yang tinggi.

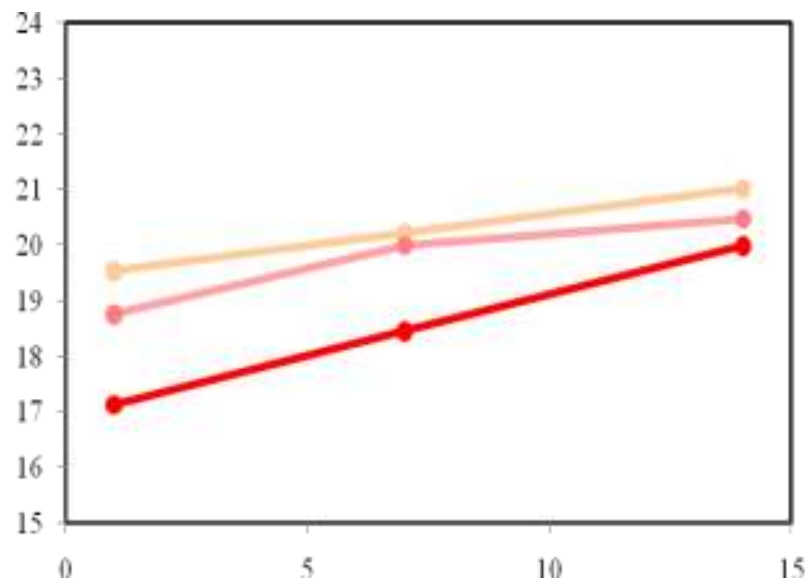

Gambar 2. Pola peningkatan kekerasan dengan suhu proses $70^{\circ} \mathrm{C}$. Poliuretan $\mathrm{A}, \mathrm{B}, \mathrm{C}$ dengan semakin meningkatnya segmen lunak, diwakili dengan gradasi warna dari muda ke gelap.

Tabel 2. Tabel laju peningkatan kekerasan dengan suhu proses $70{ }^{\circ} \mathrm{C}$

\begin{tabular}{cccccc}
\hline Poliuretan & $M_{w}$ & $k$ & $\begin{array}{c}\text { ln kekerasan } \\
\text { awal }\end{array}$ & $R^{2}$ & $\begin{array}{c}\text { Tingkatan } \\
\text { korelasi }\end{array}$ \\
\hline A & 4536 & 0.005 & 2.83 & 0.999 & tinggi \\
B & 6348 & 0.006 & 2.933 & 0.91 & tinggi \\
C & 8160 & 0.011 & 2.967 & 0.99 & tinggi \\
\hline
\end{tabular}

Pola peningkatan kekerasan poliuretan A, B, C dengan suhu proses yang lebih tinggi, $70{ }^{\circ} \mathrm{C}$, ditunjukkan pada Gambar 3. Jangkauan nilai kekerasan pada Gambar tersebut adalah 17 - 21 shore A, sedikit lebih tinggi daripada yang ditunjukkan di Gambar 
1. Hal ini dapat disebabkan oleh lebih banyaknya gugus uretan yang terbentuk. Ashgar et al (2020) melaporkan bahwa reaksi polimerisasi pada suhu $70{ }^{\circ} \mathrm{C}$ lebih cepat daripada suhu $55^{\circ} \mathrm{C}$ sehingga menghasilkan lebih banyak segmen keras (Ashgar, Qamar, Hassan, \& Alvi, 2019). Namun, kekerasan yang lebih tinggi ini juga dapat disebabkan oleh adanya produk samping. Di alam Indonesia dengan tingkat kelembaban yang tinggi, di saat awal dari pencampuran HTPB dan TDI, dengan adanya pusaran dari mixer, uap air $\left(\mathrm{H}_{2} \mathrm{O}\right)$ dapat tersedot dan terdifusi ke dalam sistem reaksi. Pada suhu tinggi, rantai HTPB lebih encer karena molekul bergerak lebih cepat sehingga jarak antar molekulnya lebih lebar. Viskositas yang lebih rendah ini menyebabkan lebih banyak uap air yang terdifusi. Berdasarkan Gambar 3, produk samping yang mungkin terbentuk adalah urea dan gelembung gas karbondioksida (Hagen, 2014). Urea diketahui memiliki gaya kohesi melebihi gaya kohesi antar gugus uretan (8.74 kcal/mol) (Matsunaga, 2010) sehingga diprediksi dapat menyebabkan poliuretan lebih keras.

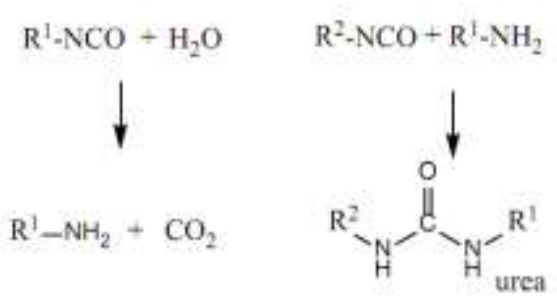

Gambar 3. Reaksi samping pada polimerisasi poliuretan dalam kelembaban udara tinggi (Hagen, 2014)

Mengenai kemiringan grafik, berbeda dengan Gambar 1 yang kemiringan grafiknya hampir sama untuk semua jenis poliuretan, pada Gambar 3 kemiringan tersebut lebih bervariasi. Lebih lanjut, dengan korelasi linier yang tinggi, laju peningkatan kekerasan tersebut dapat dilihat di Tabel 2 melalui nilai $k$. Semakin rendah nilai $k$, semakin stabil struktur higher-order dari poliuretan. Dari Tabel 2 dapat dilihat bahwa nilai $k$ dari poliuretan A dan B mirip. Namun demikian, nilai $k$ pada polimer C naik secara signifikan dari polimer A dan B, hampir dua kali lipat. Ini menunjukkan bahwa poliuretan dengan stuktur segmen lunak yang lebih banyak memiliki daya penstabilan struktur high-order yang rendah. Hal ini dapat disebabkan oleh adanya produk samping gelembung udara sesuai Gambar 3 (Hagen, 2014; A. Restasari, Abdillah, Budi, \& Hartaya, 2018). Setelah poliuretan dikeluarkan dari oven yang merupakan ruang tertutup, gelembung udara karbondioksida yang terbentuk dari reaksi samping berusaha untuk keluar dari struktur 
poliuretan yang terbentuk. Keluarnya gelembung udara ini menyebabkan pergerakan segmen keras. Dua segmen keras yang tadinya berjarak, dengan keluarnya gelembung udara, bisa menjadi lebih dekat, bahkan kemudian melekat sehingga kekerasan poliuretan meningkat. Dengan banyaknya segmen lunak yang diilustrasikan seperti lautan rantai hidrokarbon (Satoshi, 2018), semakin sulit gas karbondioksida keluar dari struktur. Dengan keluarnya gas karbondioksida sedikit demi sedikit, struktur poliuretan membutuhkan waktu yang lama untuk menjadi stabil sehingga kestabilan strukturnya rendah.

\section{KESIMPULAN}

Dalam penelitian ini pengaruh segmen lunak terhadap proses penstabilan sifat mekanik poliuretan termosetting elastomer berbasis HTPB dilakukan. Segmen lunak divariasi dengan memvariasi berat molekul HTPB. Penstabilan struktur diselidiki dengan pemantauan peningkatan kekerasan poliuretan setelah pematangan. Berdasarkan laju peningkatan kekerasan, diketahui bahwa hubungan antara segmen lunak dengan proses penstabilan kekerasan poliuretan sensitif pada suhu tinggi yang mana poliuretan dengan segmen lunak yang lebih banyak memiliki daya penstabilan struktur yang lebih rendah.

\section{UCAPAN TERIMA KASIH}

Penelitian ini dibiayai oleh pendanaan DIPA Pusat Teknologi Roket, LAPAN. Penulis berterima kasih kepada Adi Sukma dan Rahmawati Sukma dari Politeknik Sekolah Tinggi Ilmu Manajemen Industri atas dukungannya.

\section{DAFTAR PUSTAKA}

Ashgar, M. A., Qamar, I., Hassan, A., \& Alvi, M. A. (2019). Rheokinetic Analysis of HTPB-TDI Based Polyurethane Binder System. IEEE Xplore.

Dey, A., Athar, J., Sikder, A. K., \& Chattopadhyay, S. (2015). Effect of Microstructure on HTPB Based Polyurethane (HTPB-PU). Journal of Materials Science and Engineering B, 5(3-4), 145-151. https://doi.org/10.17265/2161-6221/2015.3-4.005

Dey, A., Sikder, A. K., \& Athar, J. (2017). Micro-structural Effect on Hydroxyl Terminated Poly Butadiene ( HTPB ) Prepolymer and HTPB Based Composite Propellant. Journal of Molecular Nanotechnology and Nanomedicine, 1(1), 104.

Ferry, J. D. (1980). Viscoelastic Properties of Polymers (3rd ed.). Canada: John Willey and Sons Ltd. 
Hagen, T. H. (2014). Energetic Binders for Solid Rocket Propellants Trond Heldal Hagen. Norwegian University of Life Sciences.

Hepburn, C. (1992). Polyurethane Elastomers. New York: Elsevier Science Publishers Ltd.

Manjari, R., Joseph, V. C., Sarabhai, V., \& Centre, S. (1993). Structure-Property Relationship of HTPB-Based Propellants. II Formulation Tailoring for Better Mechanical Properties. Journal of Applied Polymer Science, 279-289. https://doi.org/10.1002/app.1993.070480212

Matsunaga, K. (2010). Details of Polyurethane Creation From Materials to Applications. Tokyo: CMC Publisher.

Remakanthan, S., Kk, M., Gunasekaran, R., Thomas, C., \& Thomas, C. R. (2015). Analysis of Defects In Solid Rocket Motors Using X-Ray Radiography. In The eJournal of Nondestructive Testing (Vol. 20).

Restasari, A., \& Abdillah, L. H. (2017). Pengaruh Clearance Impeller dan Viskositas HTPB Terhadap Polimerisasi Binder Propelan. In Prosiding SIPTEKGAN XXI (pp. 331-338). Tangerang: Pusat Teknologi Penerbangan, LAPAN.

Restasari, A., Abdillah, L. H., Budi, R. S., \& Hartaya, K. (2018). Two-dimensional profiles of microvoids on hardness of bulk HTPB-based polyurethane. Journal of Physics: Conference Series, 1130(1). https://doi.org/10.1088/1742-6596/1130/1/012032

Satoshi, M. (2018). Characteristics of Cross-linked Polymer and How to Use Them. In T. Masaharu \& S. Masamitsu (Eds.), Crosslinking and Degradation of Polymer III. Tokyo: CMC Publisher.

Wibowo, H. B. (2015). Pengaruh Distribusi Fungsionalitas Polimer Terhadap Sifat Mekanik Poliuretan Berbasis HTPB. In Pengaruh Distribusi Fungsionalitas Polimer Terhadap Sifat Mekanik Poliuretan Berbasis HTPB (pp. 283-290). Indonesia Book Project.

(C) 2021 by authors. Content on this article is licensed under a Creative Commons Attribution 4.0 International license. (http://creativecommons.org/licenses/by/4.0/). 
